\title{
Existence of unprocessed a mitochondrial enzyme: YDLI78wp in the membrane fraction as an oligomeric formation with a protein-unfolding activity
}

\begin{abstract}
Gene product of the S.cerevisiae YDL178w (YDL178wp) has been identified as three proteins; firstly, it found as an actin interacting protein 2 (AIP2) using yeast two hybrid system, then re-named D-lactate dehydrogenase 2 (Dld2) because of its enzymatic activity and mitochondrial localization using fluorescent microscopy observation with the GFP-tag at the C-terminal of the protein. Finally, we have designated it Unfoldin, since it represented robust protein-unfolding activity with the Oligomeric formation. Here we show that YDL178wp exists as the two types of molecules in yeast cells, a mature sized mitochondrial protein and a precursor sized protein in the post-mitochondrial membrane fraction. This atypical intracellular presentation with multifunctional activity exhibits gene sharing or protein moonlighting, which would be represented the pragmatism of the evolutionary process.
\end{abstract}

Volume 4 Issue 2 - 2017

\author{
Akira Monkawa, Tomoko Gessei, Naomi \\ Hachiya \\ Research and Development Department, Tokyo Metropolitan \\ Industrial Technology Research Institute, Japan
}

Correspondence: Naomi Hachiya, Research and Developmen Department, Tokyo Metropolitan Industrial Technology Research Institute, Japan, Tel (+8I)355302 I I I, Fax (+8I)35530267 I, Email naomi.hachiya@iri-tokyo.jp

Received: March 20, 2017 | Published: April 06, 2017

Keywords: protein-unfolding, protein moonlighting, mitochondria, membrane, yeast

\section{Introduction}

Unfold in, a Saccharomyces cerevisiae gene product of YDL178w (YDL178wp) formed a homo-oligomeric complex consisting of 10 to 12 subunits arranged in a horseshoe-like structure with the $\sim 10 \mathrm{~nm}$ in diameter and $\sim 2 \mathrm{~nm}$ of central cavity. ${ }^{1}$ It has a chaperone-like proteinunfolding activity; aggregated protein substrates such as amyloid $b(1-$ 42 ) or a-synuclein, increases its trypsin susceptibility even under the treatment of low concentration of the protease, ${ }^{2}$ indicating that Unfold in possesses the robust protein-unfolding activity. ${ }^{3,4}$ Adenosine triphosphate (ATP), but not its hydrolysis, promoted the binding of Unfoldin to protein substrates without any specificity in vitro, ${ }^{5}$ and the removal of its $\mathrm{C}$-terminal coiled-coil region led to the dissociation of oligomer concomitant with the loss of both substrate-binding and protein-unfolding activities. ${ }^{1,2}$ Electron microscopy observation revealed that Unfoldin adapted at least in two states that correspond to either an "open state" in the presence of ATP or a "closed state" in the absence of ATP. Monomeric protein which consists of Unfoldin, ${ }^{1}$ YDL178wp, was initially identified as an actin interacting protein 2 (AIP2) using a yeast two-hybrid system, ${ }^{6}$ and then it was renamed as D-lactate dehydrogenase 2 (Dld2), ${ }^{7}$ because of the homology of Dld1p though the mitochondrial enzymatic activity is exhibited only weakly.

Here we show that YDL178wp exists two types of molecules in yeast cells: $59 \mathrm{KDa}$ of L-form and $55 \mathrm{KDa}$ of S-form. Unfoldin; the cytosolic oligomeric form of the protein with the protein-unfolding activity consisted only of the L-form, which has an unprocessed mitochondrial 36 amino acids as a mitochondrial presequence at the $\mathrm{N}$-terminal. Meanwhile, S-form exhibited smaller sized molecule as a mitochondrial mature protein, which is processed mitochondrial presequence region at the site of $\mathrm{N}$-terminal amino acids Y36 and
S37. These results exhibited that YDL178wp belongs to the proteins known as "protein moonlighting"; one gene product has various functions with alternative localization. ${ }^{8,9}$

\section{Material and methods}

\section{Protein-conformation modifying assay}

The assay was performed as described before. ${ }^{10}$ Briefly, to prepare for the assay substrate, the gene of yeast pheromone pro-alpha factor $(\mathrm{p} \alpha \mathrm{F})$ was added hexahistidine-tag at the C-terminal and amplified by PCR then inserted into the E. coli expression vector pET11a (Novagen). To express the protein, the plasmid was transformed into $E$. coli BL21 (DE3). The expressed recombinant protein was suspended in $20 \mathrm{mM}$ of $\mathrm{NaPi} \mathrm{pH} 8.0$ containing $7 \mathrm{M}$ of urea, then purified using Ni-NTA agarose column (QIAGEN). Bounded samples were eluted with $500 \mathrm{mM}$ of imidazole buffer, following dialysis in $20 \mathrm{mM}$ of $\mathrm{NaPi}$ $\mathrm{pH} 7.0$ containing $150 \mathrm{mM}$ of $\mathrm{NaCl}$. The assay was started by adding $0.1 \mathrm{mg}$ of $\mathrm{p} \alpha \mathrm{F}$ to $200 \mu \mathrm{l}$ of buffer A (10mM of HEPES-KOH $\mathrm{pH}$ of $7.4,1 \mathrm{mM}$ of DTT, and $1 \mathrm{mM}$ of $\left.\mathrm{Mg}(\mathrm{OAc})^{2}\right)$ containing $1 \mathrm{mM}$ of ATP. The mixture was incubated at $30^{\circ} \mathrm{C}$ for $15 \mathrm{~min}$ then digested with trypsin $(200 \mathrm{ng} / \mathrm{ml})$ at $16^{\circ} \mathrm{C}$ for $15 \mathrm{~min}$. Trypsin digestion was stopped by incubation with soybean trypsin inhibitor $(400 \mathrm{ng} / \mathrm{ml})$ on ice for $5 \mathrm{~min}$, followed by trichloroacetic acid (TCA) precipitation with tRNA carriers. The untrypsinized and protected $\mathrm{p} \alpha \mathrm{F}$ was evaluated by SDSPAGE and Western blotting using affinity-purified polyclonal rabbit anti-p $\alpha \mathrm{F}$ antibody as the first antibody and horseradish peroxideslinked IgG (ICN Inc, Cappel Products) as the secondary antibody. The immunoreactivity bands were visualized by ECL-prime (GE Healthcare Science) and analyzed using a Versa $\mathrm{D}^{\circ} \mathrm{C} 5000$ System (Bio-Rad). 


\section{Purification of hexahistidine-tagged unfoldin}

To obtain sufficient amounts of Unfoldin, we prepared the yeast strain expressing YDL178w under the control of ADH promoter. The gene was fused at the C-terminal with hexahistidine-tag then amplified by PCR and then inserted into aureobasidine A (AbA) selective expression vector pAUR12311 (Takara Bio Chemicals). The protease-deficient yeast strain BY2778 [MAT $\alpha$ prb1 -D1.6R pep4::HIS3 ura-3-52 his3-D200 can1 gal2] was transformed with this plasmid, grown in YPD medium containing $0.5 \mathrm{mg} / \mathrm{ml}$ of AbA at $30^{\circ} \mathrm{C}$. Cells were collected and treated with $2.5 \mathrm{mg} / \mathrm{ml}$ of zymolyase $20 \mathrm{~T}$ then homogenized using glass pestle downs homogenizer. The debris was removed by centrifugation at $3,000-\mathrm{x}$ g for $5 \mathrm{~min}$; supernatants were centrifuged at $12,000-\mathrm{xg}$ at $4^{\circ} \mathrm{C}$ for $8 \mathrm{~min}$. This pellet was used as the mitochondrial fraction. Post-mitochondrial supernatants were ultra-centrifuged at $100,000-\mathrm{xg}$ at $4{ }^{\circ} \mathrm{C}$ for $1 \mathrm{~h}$, this precipitates were used as post-mitochondrial membrane fraction. Both samples were resuspended in buffer $\mathrm{B}(50 \mathrm{mM}$ of $\mathrm{NaPi} \mathrm{pH}$ of $8.0,150 \mathrm{mM}$ of $\mathrm{NaCl}$, and $10 \mathrm{mM}$ of imidazole), subjected to Ni-NTA agarose column (QIAGEN, K.K.) equilibrated with buffer B and eluted with $500 \mathrm{mM}$ of imidazole-containing buffer $\mathrm{B}$. The elute was dialyzed against buffer $\mathrm{C}(10 \mathrm{mM}$ of HEPES-KOH pH of $7.4,50 \mathrm{mM}$ of $\mathrm{NaCl}$, and $1 \mathrm{mM}$ of DTT), passed through DEAE column (GE healthcare) equilibrated with buffer $\mathrm{C}$ and eluted with $500 \mathrm{mM}$ of $\mathrm{NaCl}$, followed by the separation with the gel filtration chromatography on a Superdex 200 column (GE healthcare) equilibrated with buffer D (50mM of $\mathrm{NaPi}$ $\mathrm{pH}$ of $7.5,10 \mathrm{mM}$ of $\mathrm{NaCl}$, and $1 \mathrm{mM}$ of $\left.\mathrm{Mg}(\mathrm{OAc})_{2}\right)$. Purified samples were evaluated by SDS-PAGE and Western blotting using antihistidine antibody (Cell Signaling Technology) as the first antibody and horseradish peroxides-linked IgG (ICN Inc, Cappel Products) as the secondary antibody. The immunoreactivity bands were visualized by ECL-prime (GE Healthcare Science) and analyzed using a Versa Doc 5000 System (Bio-Rad).

\section{Proteinase $\mathrm{K}$ digestion of $\mathrm{ScN} 2 \mathrm{a}$ cells}

For the treatment of ScN2a cells with the L- and S-form of YDL178wp, the cells were collected at the $80 \%$ confluent then suspended in the 2 volume of PBS. Cell suspension $(1 \mathrm{mg} / \mathrm{ml})$ was crushed with grass beads and the incubated with $0.1 \mathrm{mg} / \mathrm{ml}$ of the L- or S-form of samples in $10 \mathrm{mM}$ of HEPES-KOH pH of 7.4, $1 \mathrm{mM}$ of DTT, and $1 \mathrm{mM}$ of $\mathrm{Mg}(\mathrm{OAc})_{2}$ containing $1 \mathrm{mM}$ of ATP at $30^{\circ} \mathrm{C}$ for $1 \mathrm{~h}$. After this incubation, cells were resuspended in the lysis buffer $(50 \mathrm{mM}$ of Tris- $\mathrm{Cl} \mathrm{pH}$ of $7.8,150 \mathrm{mM}$ of $\mathrm{NaCl}, 0.5 \%$ sodium deoxycholate, and $0.5 \% \mathrm{NP}-40$ ) then $10 \mathrm{mg} / \mathrm{ml}$ of proteinase $\mathrm{K}$ was added. After the incubation at $37^{\circ} \mathrm{C}$ for $30 \mathrm{~min}$, cells were centrifuged with 10,000 $\mathrm{x} \mathrm{g}$ and the pellet was collected and analyzed via SDS-PAGE and Western blotting using anti-prion protein monoclonal antibody SAF83 (Cayman Chemicals)

\section{Results and discussion}

The C-terminal hexahistidine-tagged YDL178w was expressed in the protease-deficient yeast strain BY2778 under the control of ADHpromoter using aureobasidine $\mathrm{A}(\mathrm{AbA})$ selective expression vector pAUR123. Cells were grown in YPD medium containing $0.5 \mathrm{mg} / \mathrm{ml}$ of $\mathrm{AbA}^{11}$ at $30^{\circ} \mathrm{C}$. Each samples treated with zymolyase $20 \mathrm{~T}$, then cells were homogenized and fractionated into mitochondrial ${ }^{12}$ or post-mitochondrial fractions by using the centrifugation method as described in Methods section; the latter was usually used as the starting material for Unfold in preparation (Figure 1). In these experiments, mitochondrial and post-mitochondrial samples were firstly examined using two column chromatography steps, Ni-NTA and ion exchange chromatography, followed by gel filtration chromatography, respectively. From the mitochondrial fraction-derived materials, the eluted peak fraction of the gel filtration was observed at the fraction of 19 , indicating at the size of $\sim 55 \mathrm{KDa}$ monomeric sizes (Figure $2 \mathrm{~A})$. In contrast, the peak fraction from post-mitochondrial fractionderived sample was detected at the size of $\sim 700 \mathrm{KDa}$, indicating the oligomeric form (Figure 2B).

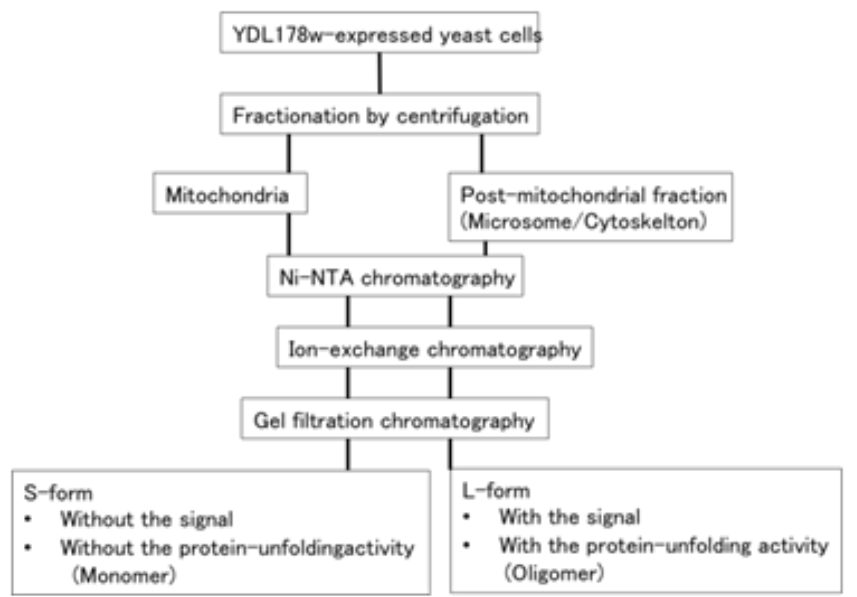

Figure I Purification scheme of YDLI78wp/Aip2p/DId2p/Unfold in. YDLI78wp was purified as described in the materials and methods. After the gel filtration, SDS-PAGE and Western blotting were performed and examined its molecular weight of them.

(A)

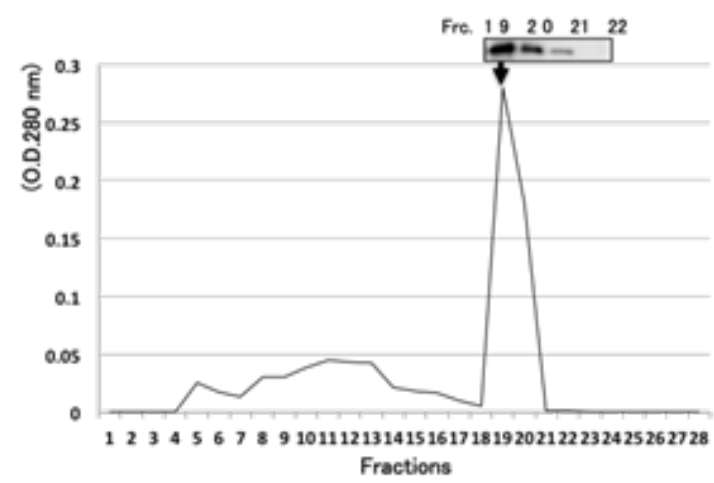

(B)

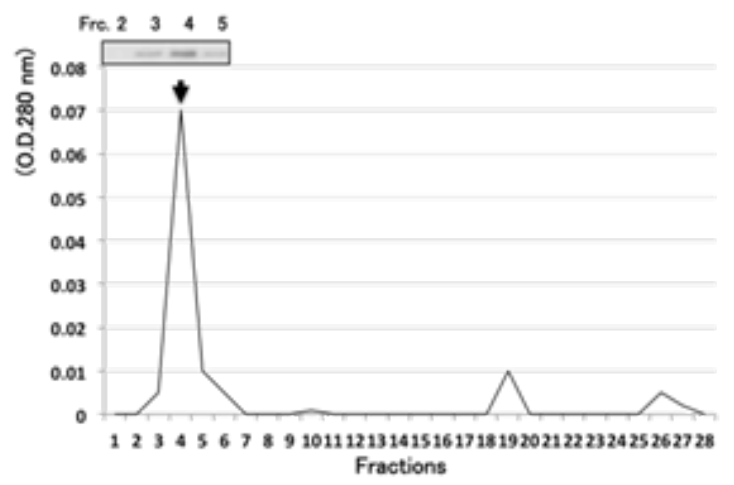

Figure 2 Oligomerization of the L-form. (A) Mitochondrial fraction-derived sample $(300 \mathrm{mg})$ and $(B)$ post-mitochondrial fraction-derived sample $(50 \mathrm{mg})$ were subjected to the gel filtration chromatography Superdex 200. Peak fractions were collected and analyzed by Western blotting using anti-histidine antibody. Allows exhibited fraction 19 (S-form) and fraction 4 (L-form) respectively. 
Next, we examined the protein-unfolding activity of eluted fractions, in the presence of ATP, using pro-alpha factor $(\mathrm{p} \alpha \mathrm{F})$ as a substrate for a protein-conformation modifying assay with trypsin susceptibility. Low-concentrate trypsin $(200 \mathrm{ng} / \mathrm{ml})$ did not degrade $\mathrm{p} \alpha \mathrm{F}$, it was protected and visualized as a band (Figure 3A \& 3B) (lanes 2 ) as much as the control (Figure 3A \& 3B) (lanes 1). When we added the purified samples from the mitochondrial monomeric fraction (Figure 2A) (fraction 19), it did not change the susceptibility of trypsin, the substrate was also protected (Figure 3A) (lane 3) indicating that the monomeric protein did not have the activity. On the other hand, the addition of the post-mitochondrial fraction (Figure 2B) (Fraction 4), the structure of $\mathrm{p} \alpha \mathrm{F}$ was unfolded and thus the trypsin susceptibility was increased (Figure 3B) (lane 3) suggesting that the oligomeric form contained the activity as we described before. ${ }^{10}$ To investigate the activity using a more highly aggregated substrate, we used ScN2a cells, ${ }^{13}$ which chronically infected the abnormal form of prion strain $22 \mathrm{~L} .{ }^{14,15}$ When the $\mathrm{ScN} 2 \mathrm{a}$ cells were treated with proteinase $\mathrm{K}$ in the presence of detergents, detergent-insoluble aggregated fragments were detected that corresponded to 0,1 and 2-sugar chain modifications, respectively (Figure 3C) (lane 1). Pre-incubation with samples from the post-mitochondrial membrane fraction under the presence of $1 \mathrm{mM}$ of ATP resulted in the disappearance of the aggregated bands (Figure 3C) (lane 3), while samples from the mitochondrial fraction did not have the activity (Figure 3C) (lane 2), three bands of prion protein were resistant to proteinase $\mathrm{K}$ as well as the control (Figure 3C) (lane 1). Without proteinase $\mathrm{K}$, each lane of panel $\mathrm{C}$ contained the same amount of the proteins.
(A)

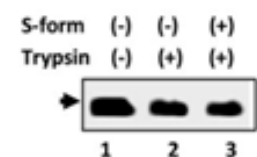

(C)

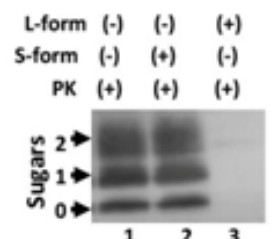

(B)

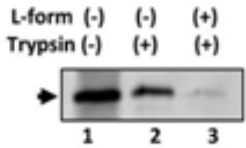

(D)

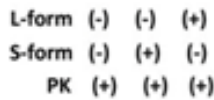

Finally, to examine the molecular weight of purified samples, we performed Western blotting using anti-histidine antibody. As shown in Figure 4A, mitochondrial derived purified samples exhibited $55-\mathrm{KDa}$ of the smaller sized band as S-form (Figure4A) (lane 1). Meanwhile, post-mitochondria derived purified sample was detected as $59-\mathrm{KDa}$ of $\mathrm{L}$-form, $55 \mathrm{KDa} \mathrm{S}$-form was observed only slightly in the same fraction (Figure 4A) (lane 2). Since the hexahistidinetag was added to the $\mathrm{C}$-terminals of the protein and the bands were detected with the anti-histidine antibody, this molecular sift seems to be caused by the deletion of the N-terminal region. Therefore, next we have analyzed the $\mathrm{N}$-terminal amino acid sequence of the $\mathrm{S}$-form using the Edman degradation method ${ }^{16}$ and found that the S-form was processed between the N-terminal amino acids Y36 and S37 (Figure 4B). Processing of this position is completely identical to the cleavage site of presequence of YDL178wp, which can be recognized by the mitochondrial processing protease Icp55. ${ }^{17}$ In accordance with this, molecular size of the L-form was same as the rabbit reticulocyte lysates synthesized precursor protein (Figure 4A) (lane 3). These results clearly showed that the S-form was the mitochondrial mature protein. The protein coded to YDL178w in S. cerevisiae was first identified as an actin-interacting protein 2 using yeast two-hybrid system ${ }^{6}$ Later, it was re-identified as a mitochondrial protein D-lactate dehydrogenase $2 ;^{7}$ however, physiological function of this protein still not has elucidated. Meantime, in the course of searching protein-unfolds from yeast cells using an in vitro protein conformation-modifying assay system with the substrate of pro-a factor, we serendipitously identified the activity ${ }^{1,2,5}$ It was also YDL178w gene product, making a C-terminal residue-dependent oligomeric form consisting of 10-12 monomeric proteins and localized yeast bud necks in the log phase. ${ }^{10}$

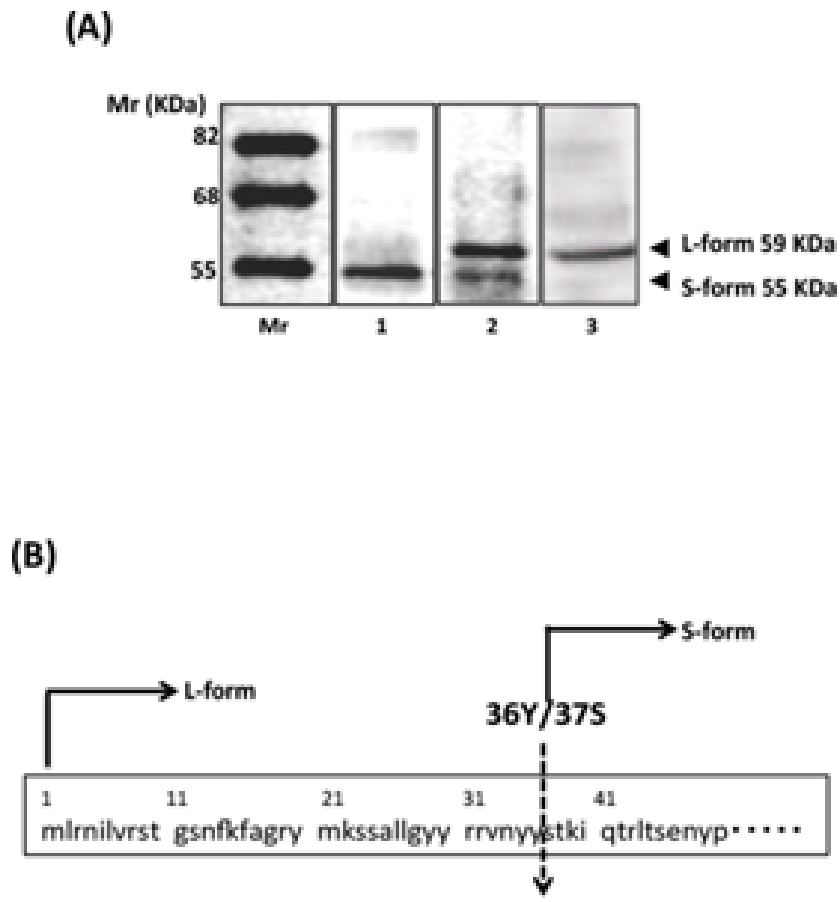

Figure 4 Existence of unprocessed form of the gene product ofYDL I 78w. (A) The mitochondrial fraction-derived (lane I) and post-mitochondrial fractionderived (lane 2) samples underwent SDS-PAGE and Western blotting using anti histidine antibody. Rabbit reticulocyte lysates synthesized YDL I78wP exhibited as the same size of the L-form (lane 3 ). $7 \mathrm{mg}$ of proteins was added in each lane. Dr. Western (Oriental Yeast) was used as a molecular weight marker. (B) Amino acid sequence around the N-terminal of YDL I78wp.The $\mathrm{S}$-form was exhibited mature sized protein, which possessed mitochondrial presequence. 
In this article we have examined two types of YDL178wp molecules, and found that the mitochondria-derived molecule is cleaved at the site of $36 \mathrm{Y} / 37 \mathrm{~S}$, which is identical to mitochondrial processing protease cleavage site in the mitochondrial matrix. ${ }^{17}$ S-form protein did not make an oligomeric form nor did it exhibit protein-unfolding activity. On the contrary, the post-mitochondrial membrane fraction-derived protein exhibited full length of protein, indicating that it possessed the presequence region. Oligomeric form of the protein; Unfoldin also modified even the highly aggregated prion protein structure; therefore, the sensitivity of proteinase $\mathrm{K}$ against prion protein significantly increased. Thus, we concluded that the monomeric protein is localized mitochondrial matrix and functions as a Dld2p, while; the oligomeric protein is localized at the outside of organelle and functions as Unfoldin with the robust proteinunfolding activity. Physiological function of Unfoldin has not clearly known, however, its characteristic relation between the localization and protein-unfolding activity ${ }^{5,10}$ would be the clue as to solve this problem.

Atypical intracellular presentation of proteins with various functions, such as our case, is so called protein moonlighting or gene sharing. ${ }^{8,9}$ This was thought that one of the economical and existential strategy for genes to get the ability to perform multiple functions with minimal genes during the course of evolution. On this point, as Butler et al pointed out, ${ }^{18}$ finding of the number of moonlighting proteins would be more increase in the future with the more development of experimental techniques such as proteomics experiments. ${ }^{19-21}$ In fact, a lot of proteins possessing the characterization of protein moonlighting have been identified so far; e.g. glucose-6-phosphate isomerase as neuroleukin, ${ }^{22-25}$ the cytokine secreted from T cells as metaroprotease $1,{ }^{26}$ oncogene $\mathrm{nm} 23$ as nucleoside-triphosphate (NDP) kinase ${ }^{27}$ lens crystalline as lactate dehydrogenase (LDH) ${ }^{28}$ Furthermore, recently, a lot of alternative transport/secretion pathways have found out as the unconventional pathway, ${ }^{29-31}$ and thus the dogma of protein transport have been changing. In this respect, the phenomenon such as protein moonlighting ${ }^{32-34}$ would be more noted in the near future, however, it would not be surprising if some enzyme acquired additional useful functions at the unusual localization because it seems an ingenious strategy of genes to survive during the evolution.

\section{Conclusion}

We have found that yeast gene product YDL178wp has two types of molecules; the mitochondrial mature sized protein as S-form and the membrane localized full-length form as L-form. Oligomeric form of YDL178wp exhibited protein-unfolding activity consisted of L-form of proteins and designated as Unfoldin; meanwhile S-form protein was processed at the N-terminal end by mitochondrial processing protease, Icp55. This atypical localization and activity would be represented protein moonlig.

\section{Acknowledgements}

None.

\section{Conflict of interest}

The author declares no conflict of interest.

\section{References}

1. Hachiya NS, Sakasegawa Y, Sasaki H, et al. oligomeric Aip2p/Dld2p forms a novel grapple-like structure and has an ATP-dependent Factin conformation modifying activity in vitro. Biochem Biophys Res Commun. 2004;320(4):1271-1276.
2. Hachiya NS, Sakasegawa Y, Sasaki H, et al. oligomeric Aip2p/Dld2p modifies the protein conformation of both properly folded and misfolded substrates in vitro. Biochem Biophys Res Commun. 2004;323(1):339344.

3. Hachiya NS, Ohkubo T, Kozuka Y, et al. More than a 100-fold increase in immunoblot signals of laser-microdissected inclusion bodies with an excessive aggregation property by oligomeric actin interacting protein 2/D-lactate dehydrogenase protein 2. Anal Biochem. 2005;347(1):106111.

4. Hachiya NS, Kaneko K. Investigation of laser-microdissected inclusion bodies. Methods Cell Biol. 2007;82:355-375.

5. Hachiya NS, Sakasegawa Y, Jozuka A, et al. Interaction of D-lactate dehydrogenase protein 2 (Dld2p) with F-actin: implication for an alternative function of Dld2p. Biochem Biophys Res Commun. 2004;319(1):78-82.

6. Amberg DC, Basart E, Botstein D. Defining protein interactions with yeast actin in vivo. Nat Struct Biol. 1995;2(1):28-35.

7. Chelstowska A, Liu Z, Jia Y, et al. Signalling between mitochondria and the nucleus regulates the expression of a new D-lactate dehydrogenase activity in yeast. Yeast. 1999;15(13):1377-1391.

8. Piatigorsky J. Gene sharing in lens and cornea: facts and implications. Prog Retin Eye Res. 1998;17(2):145-174.

9. Jeffery CJ. Multifunctional proteins: examples of gene sharing. Ann Med. 2003;35(1):28-35.

10. Nishijima K, Kaneko K, Hachiya N, et al. Calmodulin-like skin protein (CLSP) is a novel biomarker candidate for Pick's disease by Unfoldinmodified proteomic analysis. J Neurol Neurophysiol. 2012.

11. Ikai K, Takesako K, Shiomi K, et al. Structure of aureobasidin A. $J$ Antibiot (Tokyo). 1991;44(9):925-933.

12. Naomi Hachiya, Katsuyoshi Mihara, Kitaru Suda, et al. Reconstitution of the initial steps of mitochondrial protein import. Nature. 1995;376:705709 .

13. Naslavsky N, Stein R, Yanai A, et al. Characterization of detergentinsoluble complexes containing the cellular prion protein and its scrapie isoform. J Biol Chem. 1997;272(10):6324-6331.

14. Kim YS, Carp RI, Callahan SM, et al. Vacuolization, incubation period and survival time analyses in three mouse genotypes injected stereotactically in three brain regions with the $22 \mathrm{~L}$ scrapie strain. $J$ Neuropathol Exp Neurol. 1990;49(2):106-113.

15. Prusiner SB, Groth DF, Bildstein C, et al. Electrophoretic properties of the scrapie agent in agarose gels. Proc Natl Acad Sci U S A. 1980;77(5):2984-2988.

16. Aebersold R, Pipes GD, Wettenhall RE, et al. Covalent attachment of peptides for high sensitivity solid-phase sequence analysis. Anal Biochem. 1990;187(1):56-65.

17. Vögtle FN, Wortelkamp S, Zahedi RP, et al. Global analysis of the mitochondrial $\mathrm{N}$-proteome identifies a processing peptidase critical for protein stability. Cell. 2009;139(2):428-439.

18. Butler GS, Overall CM. Proteomic identification of multitasking proteins in unexpected locations complicates drug targeting. Nat Rev Drug Discov. 2009;8(12):935-948.

19. Aebersold R, Mann M. Mass spectrometry-based proteomics. Nature. 2003;422(6928):198-207.

20. Pan S, Aebersold R. Quantitative proteomics by stable isotope labeling and mass spectrometry. Methods Mol Biol. 2007;367:209-218.

21. Patterson SD, Aebersold RH. Proteomics: the first decade and beyond. Nat Genet. 2003;33 Suppl:311-323. 
22. Pelin Faik, James IH Walker, Alison AM, et al. Mouse glucose-6phosphate isomerase and neuroleukin have identical 3' sequences. Nature. 1988;332:455-456.

23. Baumann M, Brand K. Purification and characterization of phosphohexose isomerase from human gastrointestinal carcinoma and its potential relationship to neuroleukin. Cancer Res. 1988;48(24 pt 1):7018-7021.

24. Yakirevich E, Naot Y. Cloning of a glucose phosphate isomerase/ neuroleukin-like sperm antigen involved in sperm agglutination. Biol Reprod. 2000;62(4):1016-1023.

25. Watanabe H, Takehana K, Date M, et al. Tumor cell autocrine motility factor is the neuroleukin/phosphohexose isomerase polypeptide. Cancer Res. 1996;56(13):2960-2963.

26. Docherty A J, Lyons A, Smith BJ, et al. Sequence of human tissue inhibitor of metalloproteinases and its identity to elytroid-potentiating activity. Nature. 1985;318:66-69.

27. Wallet V, Mutzel R, Troll H, et al. Dictyostelium nucleoside diphosphate kinase highly homologous to $\mathrm{Nm} 23$ and Awd proteins involved in mammalian tumor metastasis and Drosophila development. J Natl Cancer Inst. 1990;82(14):1199-1202.
28. Wistow GJ, Mulders JW, de Jong WW. The enzyme lactate dehydrogenase as a structural protein in avian and crocodilian lenses. Nature. 1987;326(6113):622-624.

29. Malhotra V. Unconventional protein secretion: an evolving mechanism. EMBO J. 2013;32(12):1660-1664.

30. Ponpuak M, et al. Secretory autophagy. Curr Opin Cell Biol. 2015;35:106-116.

31. La Venuta G, Zeitler M, Steringer JP, et al. The Startling Properties of Fibroblast Growth Factor 2: How to Exit Mammalian Cells without a Signal Peptide at Hand. J Biol Chem. 2015;290(45):27015-27020.

32. Beynon RJ, Hammond D, Harman V, et al. The role of proteomics in studies of protein moonlighting. Biochem Soc Trans. 2014;42(6):16981703.

33. Gancedo C, Flores C L, Gancedo J M. The Expanding Landscape of Moonlighting Proteins in Yeasts. Microbiol Mol Biol Rev. 2016;80(3):765-777.

34. Monaghan RM, Whitmarsh AJ. Mitochondrial Proteins Moonlighting in the Nucleus. Trends Biochem Sci. 2015;40(12):728-735. 